\title{
Guest editors' introduction
}

\author{
Gabriele Kotsis • David Taniar • Ismail Khalil • \\ Eric Pardede
}

Published online: 16 March 2010

(C) Springer Science+Business Media, LLC 2010

This issue features selected papers from the International Conference on Advances in Mobile Computing and Multimedia (MoMM2008) held in Linz, Austria, in November 2426, 2008. A number of important achievements marked the sixth edition of MoMM, including being endorsed by the ACM SIGMM and the proceedings is published by the ACM press making it available in the ACM Digital Library.

This year, Multimedia Tools and Applications (MTAP) has agreed to publish the extension of MoMM2008 best papers appear in a special issue. A special thanks to MTAP Editor-in-chief, Professor Borko Fuhrt for this opportunity. We hope this current issue is a starting point of the future collaboration between MTAP and MoMM conference series.

Five papers are included in this issue. These papers have been extended from their original versions presented at the conference. The authors come from Albania, Austria, France, Germany, Japan, Spain and USA, which indicates the global audience of MoMM conference series and MTAP readers.

As general co-chairs and program co-chairs of MoMM2008, as well as the guest editors of MTAP special issue of MoMM2008, we would like to congratulate the authors of papers appeared in this issue for their achievements in MoMM2008 and their inclusion in this issue of MTAP. We would also like to thank the PC members of MoMM2008 who conducted the initial reviewing process for the conference and the MoMM2008 award cochairs for selecting the best papers.

G. Kotsis $(\square) \cdot$ I. Khalil

Johannes Kepler University Linz, Linz, Austria

e-mail: Gabriele.Kotsis@jku.at

D. Taniar

Faculty of Information Technology, Monash University, Clayton, Victoria, Australia

E. Pardede

La Trobe University, Melbourne, Australia 


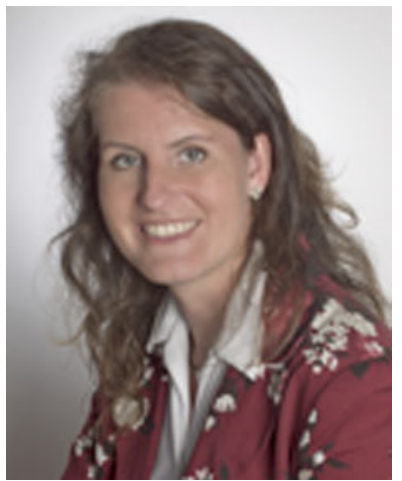

Gabriele Kotsis is holding a full professor position in computer science at Johannes Kepler University Linz. She is chairing the Department of Telecooperation with a research focus in mobile computing, multimedia and hypermedia systems as well as cooperative and collaborative systems. Research in those areas includes the investigation of methods, techniques and tools for system development as well as evaluation and analysis with focus on performance evaluation. The Department is participating in numerous national and international projects, including CRUISE, a European network of excellence in sensor networks, EuroFGI, a network of excellence on Future Generation Internet, the AustrianGrid project, or ModelCVS a project on semantics in SW and system modelling, and actively involved in the organisation of international conferences, including for example iiWAS and MoMM.

Gabriele Kotsis, born on October 29th, 1967, in Vienna, Austria, started her scientific career at the University of Vienna. She received her masters degree (1991, honored with the Award of the Austrian Computer Society), her PhD (1995, honored with the Heinz-Zemanek Preis) and the venia docendi in computer science (2000) from the University of Vienna. Before joining JKU Linz in October 2002, she was working as a researcher and teacher at the University of Vienna (1991-2001), at the Vienna University for Economics and Business Administration (2001) and at the Copenhagen Business School (2002).

Prof. Kotsis is author of numerous publications in international conferences and journals and is co-editor of several books. She is member of the OCG, the ACM and IEEE. From April 2003 to April 2007 she was president of the Austrian Computer Society.

Since October 2008 she is Vice Rector for Research at the Johannes Kepler University, Linz.

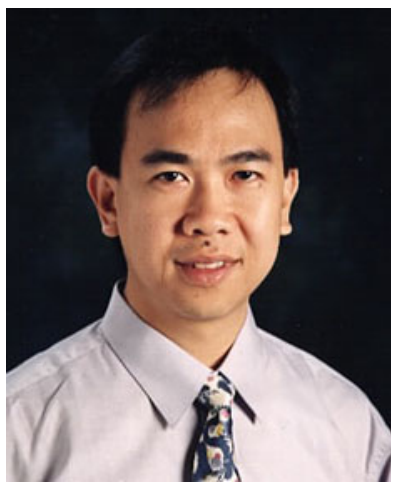

David Taniar holds Bachelors (Honours), Masters, and PhD degrees-all in Computer Science/Information Technology, with a particular speciality in Databases. He publishes extensively every year. He is currently a Senior Lecturer at the Faculty of Information Technology, Monash University, Australia. He is a founding editor-in-chief of a number of international journals, including Intl $\mathrm{J}$ of Data Warehousing and Mining, Intl $\mathrm{J}$ of Business Intelligence and Data Mining, Mobile Information Systems, Journal of Mobile Multimedia, Intl J of Web Information Systems, and Intl J of Web and Grid Services. 


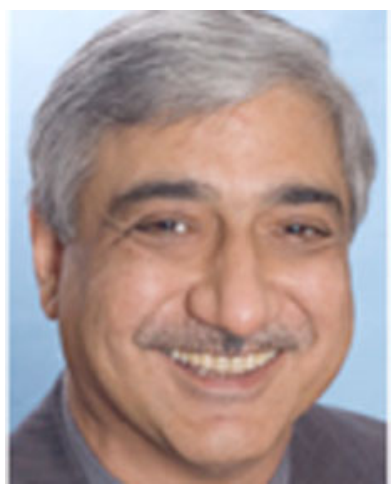

Ismail Khalil is a senior researcher and lecturer at the institute of telecooperation at Johanes Kepler University Linz, Austria since October 2002. He is the president of the international organization of Information Integration and Web-based Applications \& Services @WAS (www.iiwas.org). He holds a PhD in computer engineering and received his habilitation degree in applied computer science on his work on agents interactions in ubiquitous environments in May 2008. He is the editor of the handbook of research on Mobile Multimedia series, the book Mobile Multimedia: Communication Engineering Perspective and the book Multimedia Transcoding in Mobile and Wireless Networks. He currently teaches, consults, and conducts research in Mobile Multimedia, Agent Technologies, and the Semantic Web and is also interested in the broader business, social, and policy implications associated with the emerging information technologies. Before joining Johannes Kepler University of Linz, he was a research fellow at the Intelligent Systems Group at Utrecht University, Netherlands from 2001-2002 and the project manager of AgenCom project at the Software Competence Center Hagenberg - Austria from 2000-2001. Dr. Khalil has authored around 100 scientific publications, books, and book chapters. He serves as the editor-in-chief of the International Journal on Web Information Systems (IJWIS), Journal of Mobile Multimedia (JMM), International Journal of Mobile Computing and Multimedia Communication (IJMcMc), Advances in Next Generation Mobile Multimedia book series, and Atlantis Ambient and Pervasive Intelligence book series. He is on the editorial board of several international journals. His work has been published and presented at various conferences and workshops.

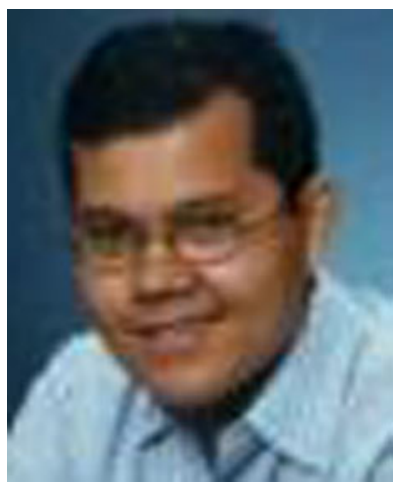

Eric Pardede completed his Doctor of Philosophy in Computer Science and Master of Information Technology from La Trobe University. He has published his research works in various books, international journals and conference proceedings. Current, he is a lecturer in software engineering and database at La Trobe University, Melbourne, Australia. 